This item was submitted to Loughborough's Research Repository by the author.

Items in Figshare are protected by copyright, with all rights reserved, unless otherwise indicated.

\title{
The effect of uphill and downhill slopes on centre of pressure movement, alignment and shot outcome in mid-handicap golfers
}

\section{PLEASE CITE THE PUBLISHED VERSION}

https://doi.org/10.1080/14763141.2019.1601250

\section{PUBLISHER}

(C) Taylor and Francis

\section{VERSION}

AM (Accepted Manuscript)

\section{PUBLISHER STATEMENT}

This is an Accepted Manuscript of an article published by Taylor \& Francis in Sports Biomechanics on 9 May 2019, available online: http://www.tandfonline.com/10.1080/14763141.2019.1601250.

\section{LICENCE}

CC BY-NC-ND 4.0

\section{REPOSITORY RECORD}

Hiley, Michael, Zarthast Bajwa, Ying Liang, and Glen Blenkinsop. 2019. "The Effect of Uphill and Downhill Slopes on Centre of Pressure Movement, Alignment and Shot Outcome in Mid-handicap Golfers". Loughborough University. https://hdl.handle.net/2134/37806. 
Sports Biomechanics ${ }^{\star *},{ }^{\star * * *-* * * *}, 2019$

\title{
The effect of uphill and downhill slopes on centre of pressure movement, alignment and shot outcome in mid-handicap golfers
}

\author{
${ }^{1}$ Michael J Hiley, ${ }^{1}$ Zarthast Bajwa, ${ }^{2}$ Ying Liang and ${ }^{1}$ Glen M Blenkinsop
}

\begin{abstract}
${ }^{1}$ School of Sport, Exercise and Health Sciences, Loughborough University, Leicestershire, LE11 3TU, UK
${ }^{2}$ Department of Physical Education, Anhui Normal University, Beijing East Road, Wuhu, China
\end{abstract}

\begin{abstract}
The aim of the study was to examine changes in centre of pressure (COP) movement, alignment and shot outcome during golf shots from flat, uphill, and downhill slopes by midhandicap golfers. Twelve male golfers hit balls with a six-iron from the flat and $5^{\circ}$ slopes while kinematics and kinetics of the swing were collected. A launch monitor measured performance outcomes. A shift in the centre of pressure was found during the backswing when playing on a slope, but disappeared during the downswing. Golfers attempted to align the body perpendicular to the slope at the start of the swing resulting in COP movement towards the lower foot, but were not able to maintain this throughout the swing, like low handicap golfers. There was no significant difference in stance width, but golfers placed the ball closer to the uphill foot on a slope. Ball speed was not significantly affected by the slope, but launch angle and ball spin were. Golfers were more likely to hit shots to the left from an uphill slope and to the right for a downhill slope. No consistent compensatory adjustments in alignment at address were found, with differences in final ball position due to lateral spin.
\end{abstract}

Keywords: golf swing, centre of pressure, biomechanics

\section{INTRODUCTION}

T Until recently the majority of golf research has taken place in controlled laboratory settings with shots taken from a flat surface (Ball \& Best, 2012; Bradshaw et al., 2009; Healy et al., 2011; Zheng, Barrentine, Fleisig, \& Andrews, 2008), whilst kinetic and kinematic data have been collected (Zheng et al., 2008; Ball \& Best, 2007; McNitt-Gray, Munaretto, Zaferiou, Requejo, \& Flashner, 2013; Okuda, Gribble, \& Armstrong, 2010). However, golf courses are variable environments designed to incorporate natural features, such as slopes, to make them more challenging. As a result, conditions can change from shot to shot, with very few shots played from a completely flat surface. Peters, Smith and Lauder (2015) found that from 953 shots played by 22 professional golfers on 16 different golf courses, approximately $80 \%$ were played from a slope of between $\pm 1^{\circ}$ and $10^{\circ}$, with an average inclination of $4.6^{\circ}$. Recently a small number of studies have attempted to incorporate the uneven nature of the golf course into research on golf swing mechanics (Blenkinsop, Liang, Gallimore, \& Hiley, 2018; Peterson \& McNitt-Gray, 2018).

Peterson and McNitt-Gray (2018) investigated the effect of altered foot placement by raising each foot independently to replicate challenging golf stances, with the ball placed at the same level as the lower foot. It was found golfers produced individualised responses to coordinate the legs and regulate impulse in such conditions. Blenkinsop et al. (2018) looked at the effect of uphill and downhill slopes (of $\pm 5^{\circ}$ in the direction of the shot) on low handicap golfers (range: -3 to 5 ) in terms of weight transfer, alignment and shot outcomes. Where weight transfer in the literature has typically referred to the movement of the centre of pressure (Ball \& Best, 2007; Koslow, 1994; Okuda et al., 2010). A typical sequence begins (Figure 1, TA - take away) with an even distribution of weight between the feet at address (Leadbetter, 1993). During the backswing the golfer's weight (as measured by centre of pressure - COP) moves towards the back foot (away from the target), before moving towards the front foot just before the start 
of the down swing (Ball \& Best, 2007). There is a rapid transfer of weight towards the front foot in the early stage of the downswing, with the transfer continuing to the front foot through to ball contact (Figure 1, TB-BC, top of backswing to ball contact). Blenkinsop et al. (2018) found that low handicap golfers followed coaching advice to set the body perpendicular to the slope and adopted a wider than normal stance to increase stability when playing from such slopes (Leadbetter, 1993; Hunter, 2010; Harmon, 2011). With the body perpendicular to the slope more weight was transferred to the lower foot, causing a general COP shift (approximately $9 \%$ closer to the lower foot) to the back foot on uphill slopes and to the front foot during downhill slopes (Figure 1). The low handicap golfers appeared to make a consistent adjustment throughout the swing for the slope, in terms of the COP pattern, suggesting that they were attempting to recreate the same swing as if on a level surface (Figure 1). The golfers also followed the advice of Leadbetter (1993) to move the ball nearer the front foot for uphill slopes and nearer to the back foot for downhill slopes.

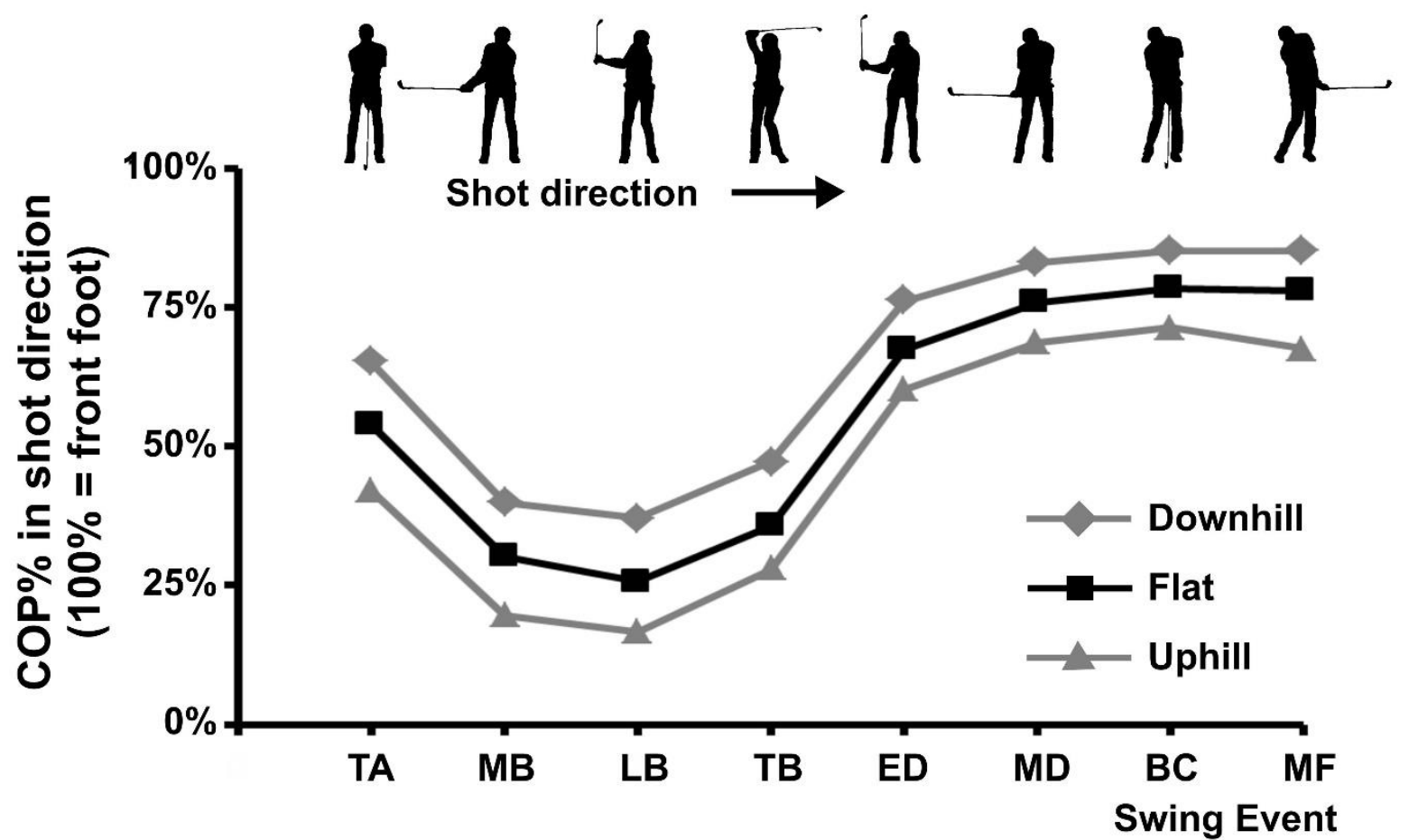

Figure 1. Swing events (Ball and Best, 2007) within the golf shot along with the weight transfer from back foot (furthest from target) to front foot for low handicap golfers playing from flat and $5^{\circ}$ slopes (Blenkinsop et al. 2018).

In addition to adjusting the pattern of weight transfer, Blenkinsop et al. (2018) confirmed the coaching predictions that golfers were more likely to hit shots to the left from an uphill slope and to the right for a downhill slope (for a right handed golfer), with the change in final shot offline position due to the lateral spin of the ball (Blenkinsop et al., 2018). No consistent compensatory adjustments in alignment at address were found. It is also suggested that playing from an uphill slope will lead to a greater launch angle and a shorter ball flight (Leadbetter, 1993; Harmon, 2011). While Blenkinsop et al. (2018) did find a significant difference in launch angle, there was no significant difference in total shot distance (i.e. ball flight and roll) for the $5^{\circ}$ slopes.

Previous research has provided a wealth of information on the differences between high and low handicap golfers (Bradshaw et al., 2009; Cheetham, Martin, Mottram, \& St Laurent, 2000; Myers et al., 2007; Okuda et al., 2010; Zheng et al., 2008). A measure of a golfer's general consistency may be inferred from his/her 
handicap (the lower the handicap the higher the skill level of the golfer) as this is determined over numerous rounds of golf. One of the key performance differences identified between low and high handicap golfers is the speed of the clubhead close to ball impact. It has been shown that lower handicap golfers are able to produce not only higher clubhead velocities (Fradkin, Sherman, \& Finch, 2004), but produce this peak velocity closer to the ball impact than higher handicap golfers (Zheng et al., 2008). As clubhead speed at ball impact is mechanically related to the subsequent ball speed and hence shot distance (Kenny, McCloy, Wallace, \& Otto, 2008), it is expected that lower handicap golfers generally hit the ball further than their higher handicap counterparts.

On flat ground Richards, Farrell, Kent and Kraft (1985) found no difference in the pattern of weight transfer in the direction of the target between high and low handicap golfers. Whereas, the range and peak velocity of the COP in the direction of the shot have both been found to be larger for higher skilled golfers (Ball \& Best, 2007b; Wallace, Graham, \& Bleakley, 1990; Koenig, Tamres, \& Mann, 1993). Likewise, Choi, Sim and Mun (2016) found that professional golfers demonstrated better dynamic balance than amateur golfers. If lower skilled golfers are less stable than higher skilled golfers the introduction of a more challenging situation, such as a slope, may lead to changes in the expected COP pattern, which may in turn impact on consistency of striking the ball. Most golfers have access to coaching advice, but whether the higher handicap golfers are able to follow it, as the low handicap golfers did, is not known.

The aim of the present study was to examine changes in COP movement, direction of aim and performance outcomes (e.g. ball speed, launch angle and offline displacement) during golf shots from flat, uphill, and downhill slopes of intermediate level golfers (handicap 10-15). It is hypothesised for uphill shots that golfers' COP will shift towards the back foot, the launch angle will increase along with ball spin to the left and golfers will place the ball closer to the front foot compared to the flat condition. For shots from a downhill slope it is hypothesised that golfers' COP will shift towards the front foot, the launch angle will decrease, with a ball spin to the right. It is hypothesised that the intermediate level golfers will make no adjustments in alignment to compensate for the slope, but will be more varied in shot outcomes compared to low handicap players (Blenkinsop et al., 2018).

\section{METHODS}

\section{Participants}

Twelve male right handed amateur golfers (age: $46 \pm 9$ [mean \pm standard deviation] years, mass: $89 \pm 16 \mathrm{~kg}$, height: $1.77 \pm 0.12 \mathrm{~m}$ ), classed as intermediate with a mean handicap of $12.1 \pm 1.9$ (range: 10 to 15) participated in the study. All golfers gave written informed consent for participation in the study that was approved by the Loughborough University ethical advisory committee.

\section{Data collection}

The procedure of Blenkinsop et al. (2018) was followed to allow comparison between low and high handicap golfers. After a self-selected warm-up, golfers hit 15 shots, with 5 shots taken from three different slope conditions (flat, uphill, and downhill), towards a point located in the middle of a net positioned three metres away (Figure 2). The order of the 15 shots over the 3 slope conditions was randomised. Golfers were instructed to hit the ball to land as close as possible to the centre line of the virtual driving range provided by the launch monitor. Golfers used their own six-iron, wore 
their own golf shoes and golf glove, and were provided with the same golf balls (Titleist DT Solo, Titleist, Massachusetts, USA). All shots were performed from the Stewart platform of a Computer Assisted Rehabilitation Environment (CAREN) system (Motek Medical, Amsterdam, Netherlands) which was used to create uphill and downhill slopes of $5^{\circ}$ (Figure 2). An artificial grass golf driving range mat was positioned on top of the platform with two sections cut to provide non-overlapping coverage of the force plates. Force data were collected using two $0.4 \times 0.6 \mathrm{~m}$ force plates (FP4060-07, Bertec Corporation, Ohio, USA) sampling at $1000 \mathrm{~Hz}$. Kinematic data were collected using 12 Bonita B10 cameras (Vicon, Oxford Metrics Group, UK) sampling at $250 \mathrm{~Hz}$. The origin of the capture volume $(3 \times 3 \times 3 \mathrm{~m})$ was positioned at the front centre of the two force plates and the global coordinate system was set with positive $\mathrm{x}$ in the direction of the shot and positive $z$ pointing upwards (Figure 2). The participant marker set consisted of 45 markers used to track full body motion, the club was modelled using retroreflective tape positioned at three points along the shaft and two markers placed on the heel and toe end of the club and one on the top of the shaft (top of the grip). The ball was modelled using retro-reflective tape on its surface and was additionally tracked using a Foresight GC2 launch monitor (Foresight Sports, US). The launch monitor was levelled using a spirit level and aligned to the global $x$ direction using two reflective markers prior to data collection. The simulated ball flight derived from the launch monitor data was projected onto a screen in front of the golfer to provide feedback of the shot outcome (Figure 2). A further four markers were attached to the Stewart platform surface to track its position and orientation to correct for errors introduced into the force measurements due to the slope of the platform (Preuss \& Fung, 2004).

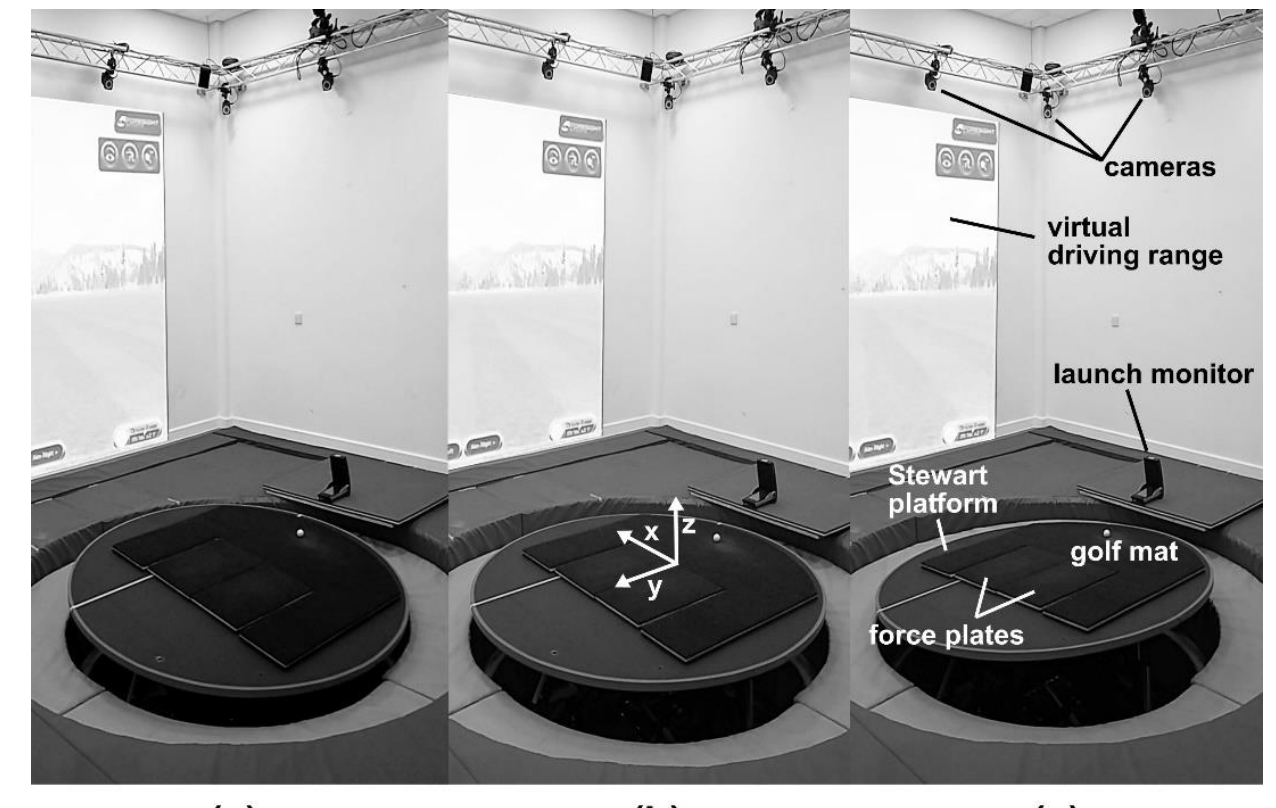

(a)

(b)

(c)

Figure 2. Data collection set up with (a) uphill (b) flat and (c) downhill slopes created by the Stewart platform of the CAREN system.

\section{Data Analysis}

Force plate data are normally expressed relative to a static global coordinate system. Movement of the platform away from the neutral orientation and position at system calibration results in an offset to force plate outputs (Preuss \& Fung, 2004). BodyLanguage code was used to reconstruct the corners of the force plates based on the four markers surrounding the platform. These points were used to recreate the 
force plate local coordinate systems so that COP and feet markers could be transformed into the same coordinate system for COP to be calculated relative to feet marker positions. Data from the two force plates were combined and COP was smoothed using a $15 \mathrm{~Hz}$ Butterworth low pass digital filter (Ball, Best, \& Wrigley, 2001; Winter, 1995; Ball \& Best 2007b). The COP in the direction of the shot was normalised to a percentage of the distance between the right and left foot centres (average of heel and toe marker for each foot), with $0 \%$ representing the back foot (right) and 100\% the front foot (left). Eight events commonly used as coaching indicators were identified during the golf swing action (Figure 1, Table 1) so that COP at these key positions could be evaluated for each slope condition (Ball \& Best, 2007).

Table 1. Definition of golf swing events as used by Ball and Best (2007)

\begin{tabular}{llc}
\hline Event & Description & Label \\
\hline Takeaway & First backward movement of the club & TA \\
Mid backswing & Club shaft parallel to horizontal plane & MB \\
Late backswing & Club shaft perpendicular to horizontal plane & LB \\
Top backswing & Instant before shaft begins downswing & TB \\
Early downswing & Club shaft perpendicular to horizontal plane & ED \\
Mid downswing & Club shaft parallel to horizontal plane & MD \\
Ball contact & Instant of club contact with ball & BC \\
Mid follow-through & Club shaft parallel to horizontal plane & MF \\
\hline
\end{tabular}

The position of the ball at take away (TA) was expressed as a percentage of the distance between the right and left foot centres and the distance on the $y$-axis from the point of mid stance (Figure 3). The absolute distance between the foot centres was also recorded for each shot. The alignment of the golfer at take away and ball contact was assessed as in Burden, Grimshaw and Wallace (1998) from the projection of the lines between foot, hip and shoulder centres onto the horizontal plane of the global coordinate system and was measured relative to the direction of the shot (global $x$ direction, Figure 3). An angle of zero corresponds to parallel to the line from tee to target with negative angles indicating a setup pointing to the left of target and positive angle pointing to the right (Wheat, Vernon, \& Milner, 2007). The inclination angle of the hips and shoulders relative to the slope was determined at take away from the projection of the lines between hip and shoulder joint centres onto the frontal plane of the global coordinate system.

Performance outcomes were measured using the Foresight GC2 launch monitor and included: ball speed (at launch), launch angle (relative to the horizontal plane), azimuth (initial direction angle of the ball relative to the target line, positive measured to the right of target), side spin (direction and magnitude, positive representing a clockwise spin), offline distance (perpendicular distance the ball would have landed away from the target line, positive measured to the right of the target line), carry distance (distance of ball flight) and the total shot distance (including roll after landing). 


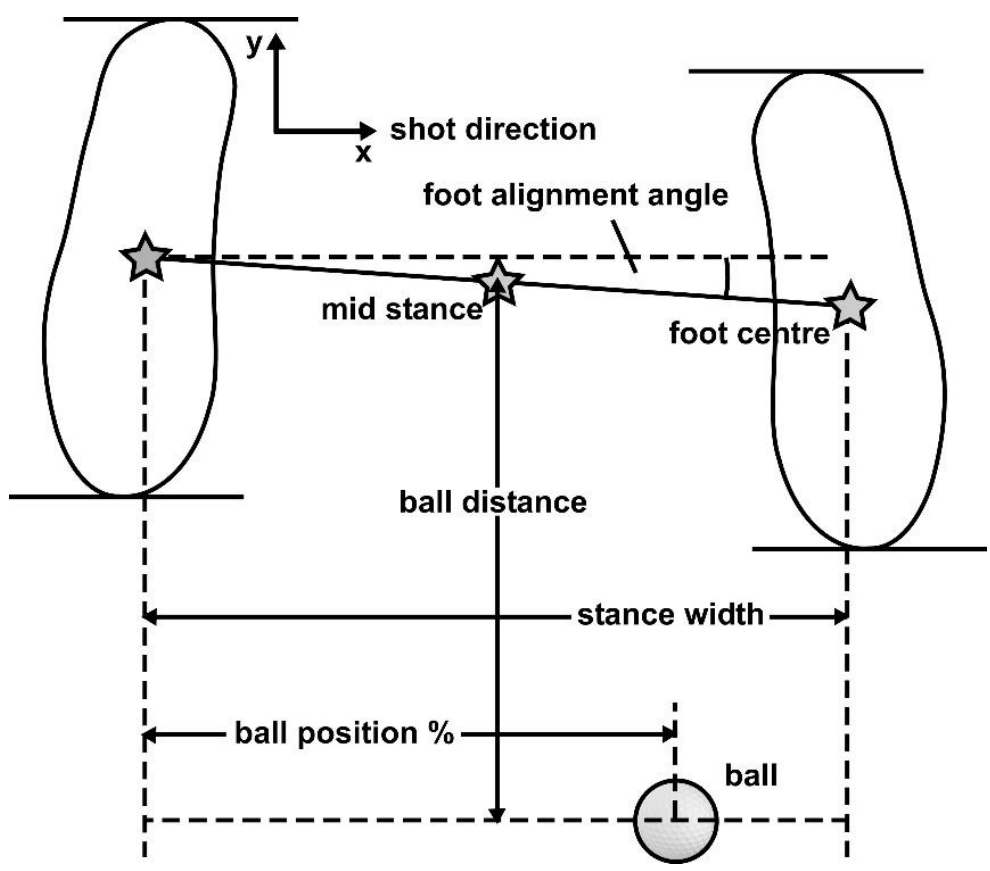

Figure 3. Definition of ball and stance measures.

\section{Statistical Analysis}

Trials were combined to create a mean score for each subject under each condition (flat, uphill, downhill). Repeated measures one-way ANOVAs were used to assess the differences in COP position, alignment and performance outcomes between flat, uphill and downhill slopes. Post hoc tests were made using multiple repeated measures t-tests with a Bonferroni correction. The procedure was repeated for the COP and performance measures on the individual standard deviation (SD) of each measure for each golfer to determine whether the golfers were more variable when playing on a slope compared to the flat. In order to establish performance differences between the lower (Blenkinsop et al., 2018) and higher handicap golfers, T-tests (1-tailed) were conducted on the performance outcomes data from shots taken on the flat, including ball speed, total distance and the range of the offline distance. Two-tailed T-tests were used for comparing launch angle, azimuth and side spin between the two groups as the direction of the difference was unknown. Comparisons were also made using the individual SD of the performance measures to determine whether the higher handicap golfers were more variable in their outcomes than the low handicap golfers. All data were assessed for normality by the Shapiro-Wilk test and sphericity by Mauchly's test. All data were found to be normally distributed, and for those data that violated the assumption of sphericity a Greenhouse-Geisser correction was used (Field, 2009).

\section{RESULTS}

A Comparisons between the low (Blenkinsop et al, 2018) and high handicap golfers revealed significantly: higher ball speed, greater shot distance (carry and total), and reduced offline distance for the low handicap (higher skilled) golfers (Table 2). The high handicap (lower skilled) golfers were more variable in ball speed and shot distance (carry and total) compared to the low handicap golfers (Table 2). 
Table 2. Results of the t-tests comparing shot outcomes from the flat condition of the high handicap and low handicap (Blenkinsop et al., 2018) golfers

\begin{tabular}{|c|c|c|c|c|c|c|}
\hline & Mean & $\mathrm{t}$ & $\mathrm{p}$ & SD & $\mathrm{t}$ & $\mathrm{p}$ \\
\hline \multicolumn{7}{|l|}{ Ball Speed (mph) } \\
\hline Low handicap & $123.2 \pm 4.3$ & \multirow{2}{*}{6.7} & \multirow{2}{*}{0.010} & $2.1 \pm 0.7$ & \multirow[t]{2}{*}{-4.1} & \multirow[t]{2}{*}{0.004} \\
\hline High handicap & $106.9 \pm 7.5$ & & & $6.5 \pm 3.1$ & & \\
\hline \multicolumn{7}{|l|}{ Launch Angle $\left({ }^{\circ}\right)$} \\
\hline Low handicap & $15.5 \pm 1.7$ & \multirow[t]{2}{*}{-1.4} & \multirow[t]{2}{*}{0.025} & $2.1 \pm 1.0$ & \multirow[t]{2}{*}{0.58} & \multirow[t]{2}{*}{0.397} \\
\hline High handicap & $17.3 \pm 4.1$ & & & $1.9 \pm 1.1$ & & \\
\hline \multicolumn{7}{|l|}{ Azimuth $\left(^{\circ}\right)$} \\
\hline Low handicap & $-0.5 \pm 2.1$ & \multirow[t]{2}{*}{1.3} & \multirow[t]{2}{*}{0.181} & $1.9 \pm 0.8$ & \multirow[t]{2}{*}{-1.1} & \multirow[t]{2}{*}{0.218} \\
\hline High handicap & $-1.9 \pm 3.0$ & & & $2.6 \pm 1.6$ & & \\
\hline \multicolumn{7}{|l|}{ Side Spin (rpm) } \\
\hline Low handicap & $53.8 \pm 485.3$ & \multirow[t]{2}{*}{0.5} & \multirow[t]{2}{*}{0.053} & $457.1 \pm 180.8$ & \multirow[t]{2}{*}{-1.5} & \multirow[t]{2}{*}{0.094} \\
\hline High handicap & $-104.3 \pm 965.4$ & & & $682.5 \pm 472.8$ & & \\
\hline \multicolumn{7}{|l|}{ Carry (yards) } \\
\hline Low handicap & $172.0 \pm 5.7$ & \multirow[t]{2}{*}{5.3} & \multirow[t]{2}{*}{0.017} & $4.6 \pm 1.7$ & \multirow[t]{2}{*}{-2.2} & \multirow[t]{2}{*}{0.010} \\
\hline High handicap & $144.4 \pm 16.9$ & & & $13.7 \pm 12.4$ & & \\
\hline \multicolumn{7}{|l|}{ Total distance (yards) } \\
\hline Low handicap & $185.9 \pm 4.6$ & \multirow{2}{*}{5.2} & \multirow{2}{*}{0.002} & $4.7 \pm 1.8$ & \multirow[t]{2}{*}{-2.4} & \multirow[t]{2}{*}{0.037} \\
\hline High handicap & $163.0 \pm 14.6$ & & & $10.5 \pm 7.1$ & & \\
\hline \multicolumn{7}{|l|}{ Range offline (yards) } \\
\hline Low handicap & $46.2 \pm 11.9$ & \multirow[b]{2}{*}{-1.8} & \multirow[b]{2}{*}{0.044} & & & \\
\hline High handicap & $59.9 \pm 23.8$ & & & & & \\
\hline
\end{tabular}

A consistent shift in the position of the COP throughout the golf swing for uphill and downhill slopes was not found for the high handicap golfers (Figure 4). Repeated measures one-way ANOVAs showed there were significant differences between the position of the COP at each swing event up to the top of the backswing (TB), but there were none beyond this point (Table 3). The general pattern of the centre of pressure remained similar between the three different conditions (Figure 4). The repeated measures one-way ANOVAs performed on the individual standard deviations at each swing event showed only one statistically significant difference, at ball contact (Table 3). Post-hoc tests showed that golfers were less variable at ball contact for the downhill condition compared to the flat (mean difference 2.1\%, $p=0.027$ ).

At address (take away) there were no significant differences in stance width for the three slope conditions (Table 4). There was a significant difference in ball position (percentage distance between the back and front foot). Post-hoc tests identified no difference between the flat and the uphill condition (Table 4). However, the ball was placed significantly further forward (towards the front foot) in the stance for the uphill and flat conditions compared to downhill (Table 4). There were no significant differences in the distance the ball was placed in front of the golfers' body (Table 4, ball distance) for any of the conditions. 


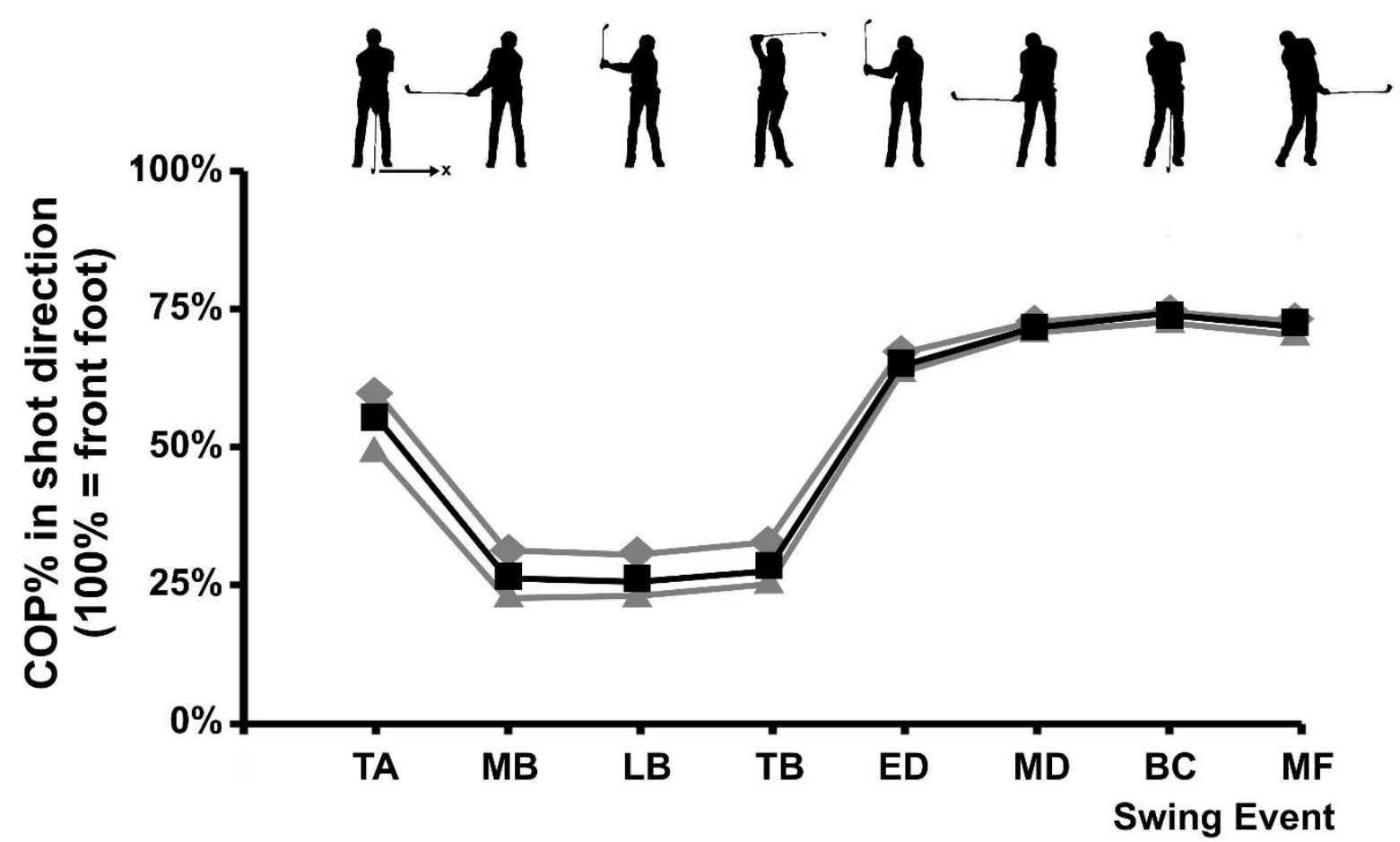

Figure 4. Group mean position of COP between the back foot (0\%) and front foot $(100 \%)$ for flat (black squares), uphill (grey triangles) and downhill (grey diamonds) lies at each swing event (Table 1).

Table 3. The position of centre of pressure (group mean \pm standard deviation) between the back foot $(0 \%)$ and front foot $(100 \%)$ for flat, uphill and downhill conditions at each swing event (Table 1) along with average individual standard deviations (SD)

\begin{tabular}{|c|c|c|c|c|c|c|c|c|}
\hline & \multicolumn{8}{|c|}{ COP location (\% of stance width) } \\
\hline & TA & MB & LB & TB & ED & MD & $\mathrm{BC}$ & MF \\
\hline Flat $(\mathrm{F})$ & $56.4 \pm 5.3$ & $27.0 \pm 10.8$ & $26.0 \pm 13.4$ & $27.4 \pm 12.1$ & $65.9 \pm 7.7$ & $72.5 \pm 10.0$ & $74.2 \pm 13.9$ & $72.2 \pm 18.4$ \\
\hline Uphill (U) & $50.2 \pm 6.1$ & $23.5 \pm 10.9$ & $23.9 \pm 11.4$ & $26.0 \pm 9.1$ & $64.3 \pm 7.6$ & $71.3 \pm 9.6$ & $73.5 \pm 15.9$ & $70.9 \pm 22.9$ \\
\hline Downhill (D) & $61.0 \pm 7.1$ & $32.2 \pm 12.8$ & $30.8 \pm 16.1$ & $33.0 \pm 14.5$ & $67.0 \pm 9.3$ & $72.7 \pm 9.9$ & $74.9 \pm 11.5$ & $73.6 \pm 16.6$ \\
\hline \multicolumn{9}{|l|}{ ANOVA: } \\
\hline F stat & 24.6 & 21.2 & 8.5 & 4.9 & 1.8 & 0.6 & 0.3 & 0.6 \\
\hline$p$ value & $<0.001$ & $<0.001^{a}$ & $0.008^{a}$ & $0.035^{a}$ & $0.211^{a}$ & 0.585 & 0.763 & 0.570 \\
\hline \multicolumn{9}{|c|}{ mean differences: } \\
\hline Fvs. U & $6.2^{* \star *}$ & 3.5 & 2.2 & 1.4 & 1.6 & 1.2 & 0.7 & 1.3 \\
\hline Fvs. D & $-4.6^{\star \star}$ & $-5.2^{\star \star \star \star}$ & $-4.7^{\star \star}$ & $-5.6^{*}$ & -1.1 & -0.3 & -0.7 & -1.4 \\
\hline \multirow[t]{3}{*}{ Uvs. D } & $-10.9^{* * \star *}$ & $-8.7^{\star \star \star \star}$ & $-6.9^{*}$ & -7.0 & -2.8 & -1.5 & -1.4 & -2.7 \\
\hline & \multicolumn{8}{|c|}{ Average SD COP location (\% of stance width) } \\
\hline & TA & MB & LB & TB & ED & MD & $\mathrm{BC}$ & MF \\
\hline Flat $(F)$ & $5.3(3.9)$ & $3.2(2.9)$ & $3.1(2.9)$ & $4.8(4.3)$ & $3.2(3.0)$ & $3.5(3.4)$ & $4.9(4.6)$ & $5.6(4.8)$ \\
\hline Uphill (U) & $5.2(4.0)$ & $2.2(2.1)$ & $2.3(2.2)$ & $4.2(4.1)$ & $4.9(4.5)$ & $3.8(3.3)$ & $4.8(4.4)$ & $4.9(4.2)$ \\
\hline Downhill (D) & $4.2(3.7)$ & $2.9(2.7)$ & $3.6(3.1)$ & $5.3(4.5)$ & $2.5(2.2)$ & $3.2(2.9)$ & $2.8(2.6)$ & $4.6(3.4)$ \\
\hline \multicolumn{9}{|l|}{ ANOVA: } \\
\hline F stat & 0.1 & 1.8 & 3.1 & 0.1 & 6.5 & 0.3 & 3.9 & 0.9 \\
\hline$p$ value & $0.816^{\mathrm{a}}$ & 0.194 & 0.063 & $0.819^{\mathrm{a}}$ & 0.060 & 0.728 & 0.033 & 0.420 \\
\hline
\end{tabular}

Note: Significant comparisons are indicated by $*(\mathrm{p}<0.05) * *(\mathrm{p}<0.01) * * *(\mathrm{p}<0.005), * * * *(\mathrm{p}<0.001)$; tests requiring a Greenhouse-Geisser correction are indicated by ${ }^{\mathrm{a}}$. 
Table 4. T Foot and ball positions (mean \pm standard deviation) at take away (TA) and shoulder, hip and foot angles at take away and ball contact (BC) for flat, uphill, and downhill

\begin{tabular}{|c|c|c|c|c|c|c|c|c|c|c|}
\hline \multirow[b]{3}{*}{ Swing event } & \multirow{3}{*}{$\begin{array}{l}\text { Stance width } \\
\qquad(\mathrm{mm})\end{array}$} & \multirow{3}{*}{$\begin{array}{c}\text { Ball position } \\
\text { (\%) }\end{array}$} & \multirow{3}{*}{$\begin{array}{l}\text { Ball distance } \\
\qquad(\mathrm{mm})\end{array}$} & \multirow{3}{*}{$\begin{array}{c}\text { Foot angle }\left(^{\circ}\right) \\
\text { Alignment } \\
\text { TA }\end{array}$} & \multicolumn{3}{|c|}{ Hip angles $\left(^{\circ}\right)$} & \multicolumn{3}{|c|}{ Shoulder angles $\left(^{\circ}\right)$} \\
\hline & & & & & \multicolumn{2}{|c|}{ Alignment } & \multirow{2}{*}{$\begin{array}{l}\text { Tilt } \\
\text { TA }\end{array}$} & \multicolumn{2}{|c|}{ Alignment } & \multirow{2}{*}{$\begin{array}{l}\text { Tilt } \\
\text { TA }\end{array}$} \\
\hline & & & & & TA & $B C$ & & TA & $\mathrm{BC}$ & \\
\hline Flat $(\mathrm{F})$ & $472.7 \pm 50.8$ & $55.9 \pm 6.7$ & $739.5 \pm 34.2$ & $0.6 \pm 2.5$ & $-2.6 \pm 5.1$ & $-24.4 \pm 9.4$ & $1.4 \pm 3.6$ & $0.3 \pm 4.5$ & $1.0 \pm 8.7$ & $11.9 \pm 3.7$ \\
\hline Uphill (U) & $476.9 \pm 44.4$ & $58.1 \pm 7.7$ & $750.7 \pm 31.3$ & $1.0 \pm 2.7$ & $-4.9 \pm 6.0$ & $-22.8 \pm 9.7$ & $0.9 \pm 4.2$ & $-0.5 \pm 4.5$ & $2.0 \pm 9.7$ & $11.4 \pm 3.4$ \\
\hline Downhill (D) & $461.9 \pm 51.6$ & $50.9 \pm 7.4$ & $753.2 \pm 40.3$ & $1.1 \pm 3.1$ & $-0.9 \pm 6.3$ & $-24.8 \pm 8.3$ & $0.7 \pm 3.4$ & $2.0 \pm 5.8$ & $0.1 \pm 7.9$ & $9.7 \pm 12.2$ \\
\hline \multicolumn{11}{|l|}{ ANOVA: } \\
\hline F statistic & 2.4 & 11.8 & 1.9 & 0.6 & 13.4 & 3.3 & 1.3 & 3.2 & 4.7 & 0.3 \\
\hline$p$ value & 0.115 & $0.003^{a}$ & $0.190^{\mathrm{a}}$ & 0.581 & $<0.001$ & 0.056 & 0.304 & $0.095^{\mathrm{a}}$ & $0.041^{\mathrm{a}}$ & $0.611^{\mathrm{a}}$ \\
\hline \multicolumn{11}{|l|}{$\begin{array}{l}\text { mean } \\
\text { differences: }\end{array}$} \\
\hline Fvs. U & -4.3 & -2.3 & -11.2 & -0.4 & 2.3 & -1.6 & 0.5 & 0.9 & -1.0 & 0.5 \\
\hline F vs. D & 10.8 & $5.0^{* * *}$ & -13.7 & -0.6 & $-1.7^{*}$ & 0.3 & 0.7 & -1.7 & $0.9^{*}$ & 2.2 \\
\hline U vs. D & 15.0 & $7.2^{*}$ & -2.5 & -0.1 & $-4.0^{\star * *}$ & 1.9 & 0.2 & -2.5 & 1.9 & 1.7 \\
\hline
\end{tabular}

Note: Significant comparisons are indicated by $*(\mathrm{p}<0.05), * *(\mathrm{p}<0.01), * * *(\mathrm{p}<0.005), * * * *(\mathrm{p}<0.001)$; tests requiring a Greenhouse-Geisser correction are indicated by ${ }^{\mathrm{a}}$.

There were no significant differences in foot and shoulder alignment during the three different conditions at take away (Table 4), however, there was for hip alignment. For an uphill slope hip alignment was significantly smaller (pointing to the left of target) compared to the downhill condition (Table 4). The hip and shoulder inclination angle relative to the surface was not significantly different between the three slope conditions. At ball contact, there was a significant difference in shoulder alignment, where on the downhill slope shoulder alignment was significantly smaller (closer to the intended shot direction) than the flat condition.

Table 5. Performance outcomes measured (mean \pm standard deviation) by the launch monitor for flat, uphill, and downhill

\begin{tabular}{|c|c|c|c|c|c|c|}
\hline & $\begin{array}{l}\text { Ball speed } \\
(\mathrm{mph})\end{array}$ & $\begin{array}{c}\text { Launch angle } \\
\left({ }^{\circ}\right)\end{array}$ & $\begin{array}{l}\text { Azimuth } \\
\left({ }^{\circ}\right)\end{array}$ & $\begin{array}{l}\text { Side spin } \\
\text { (rpm) }\end{array}$ & $\begin{array}{l}\text { Distance } \\
\text { (yards) }\end{array}$ & $\begin{array}{l}\text { Offline } \\
\text { (yards) }\end{array}$ \\
\hline Flat (F) & $106.9 \pm 7.5$ & $17.3 \pm 4.2$ & $-1.9 \pm 3.0$ & $-104.3 \pm 965.4$ & $163.0 \pm 14.6$ & $-8.9 \pm 11.6$ \\
\hline Uphill (U) & $108.2 \pm 7.5$ & $20.4 \pm 4.3$ & $-2.4 \pm 2.8$ & $-387.2 \pm 861.2$ & $164.5 \pm 15.7$ & $-15.6 \pm 14.2$ \\
\hline Downhill (D) & $108.7 \pm 7.7$ & $14.1 \pm 3.6$ & $-1.5 \pm 2.6$ & $146.5 \pm 902.8$ & $166.2 \pm 14.9$ & $-4.8 \pm 12.7$ \\
\hline \multicolumn{7}{|l|}{ ANOVA: } \\
\hline F stat & 1.5 & 77.1 & 1.3 & 7.5 & 1.2 & 11.2 \\
\hline $\mathrm{p}$ value & $0.242^{\mathrm{a}}$ & $<0.001$ & 0.290 & 0.003 & $0.315^{\mathrm{a}}$ & $<0.001$ \\
\hline \multicolumn{7}{|c|}{ mean differences: } \\
\hline F vs. U & -1.3 & $-3.2 * * * *$ & 0.5 & 282.9 & -1.5 & 6.7 \\
\hline F vs. D & -1.8 & $3.2 * * * *$ & -3.8 & -250.7 & -3.3 & -4.2 \\
\hline U vs. D & -0.6 & $6.4 * * * *$ & -0.9 & $-533.6 * * *$ & -1.8 & $-10.9^{*}$ \\
\hline
\end{tabular}

Note: Significant comparisons are indicated by $*(\mathrm{p}<0.05), * * *(\mathrm{p}<0.005), * * * *(\mathrm{p}<0.001)$; tests requiring a Greenhouse-Geisser correction are indicated by ${ }^{\mathrm{a}}$.

Performance outcomes measured by the Foresight GC2 launch monitor showed no significant difference in ball speed, shot distance, or azimuth between the three slopes (Table 5). There were significant differences for launch angle between all three conditions (Table 5), with launch angle increasing with slope. There were no significant 
differences in ball spin between the flat and the two slopes, however, there was a significant difference between uphill and downhill, with greater spin to the left from an uphill slope (Table 5). Shots from the uphill slope ended up significantly further to the left of the target than those from the downhill slope (Table 5). The repeated measures one-way ANOVA performed on the individual standard deviations of the shot performance measures revealed no statistically significant differences.

\section{DISCUSSION AND IMPLICATIONS}

The aim of the present study was to examine changes in COP movement, direction of aim (alignment) and performance outcomes during golf shots from flat, uphill, and downhill slopes by intermediate standard golfers. A CAREN system was used to create the different slopes and collect kinetic and kinematic data. The golfers used in the present study were found to be of lower standard than those used by Blenkinsop et al. (2018) by dint of not only their handicap, but in terms of the distance they hit the ball (i.e. ball speed, carry and total distance) and the accuracy with which they hit the ball (i.e. range of offline distance from the target line). Determining how the group of intermediate level golfers responded to the different slopes compared to low handicap golfers provides useful information for both players and coaches.

Previous research has found relationships between clubhead speed at ball contact and COP motion (range and peak velocity) in the direction of the shot (Ball \& Best, 2007b; Koenig et al., 1993; Wallace et al., 2010). Statistical analyses found no significant differences in the range and peak velocity of the COP between high and low handicap golfers, despite there being a significant difference in ball speed between the two groups (Table 2). The difference in ball speed and shot distance between the two groups does not appear to be as a result of the COP range or peak velocity. Richards et al. (1984) also reported that the COP movement from back foot to front foot was very similar between high and low skilled golfers. Determining how the differences in ball speed were generated by the two groups requires further investigation of the kinematics of the swing which is beyond the scope of the present study.

The general pattern of the COP within the stance at the defined swing instances (Figure 4) followed a similar pattern to that reported by Ball and Best (2007). It was hypothesised that introducing a slope would lead to a systematic shift in COP throughout the swing towards the lower of the two feet, as found by Blenkinsop et al. (2018) for low handicap golfers (Figure 1). Although there was some evidence for such a shift towards the lower foot at the start of the swing (Figure 4, Table 3), this change was gone after the top of the backswing (TB). The initial shift at address appears to be confirmed by the hip and shoulder inclination angles (Table 4). After the top of the backswing the COP path moved to the same pattern as if the golfers were on the flat surface (Figure 4). Compared to the low handicap golfers, the golfers in the present study had more weight on the foot that was higher up the slope. Rather than staying perpendicular to the slope as recommended by the coaching literature (Leadbetter, 1993; Harmon, 2011) the golfers were leaning into the slope. For an uphill slope, standing upright (relative to gravity), rather than perpendicular to the slope, would effectively steepen the path of the club towards the ball relative to the surface, whereas for the downhill slope this would lead to shallowing the path increasing the risk of striking the ground behind the ball (Harmon, 2011). That is, if the golfer performs the same swing (i.e. as if playing on a flat surface) but the playing surface has been rotated to produce a downhill slope, the angle between the club trajectory and the surface becomes smaller (shallower), compared to playing from the flat. If the club is closer to the surface on the approach to ball contact, there is an increased risk of striking the 
surface before the ball. Given that the golfers in the present study were unable to maintain the shift in COP pattern through the golf swing, this may explain why intermediate and novice golfers find playing off a downhill slope particularly difficult (Harmon, 2011).

In order to alleviate the above problem of playing from a slope the coaching literature (Harmon, 2011; Leadbetter, 1993) advises moving the ball closer the front foot for uphill slopes and closer the back foot for downhill slopes. There were no statistically significant differences in ball position between the flat and the uphill slope (Table 4), however, the ball was placed significantly closer to the front foot for the uphill condition compared to the downhill condition (Table 4), and the ball was placed significantly closer to the back foot on the downhill slope compared to the flat (Table 4). It appears that for higher handicap golfers this is achieved on the downhill slope by narrowing the stance, whereas the low handicap golfers achieved this with a wider stance (Blenkinsop et al., 2018).

The coaching advice for playing on uphill and downhill slopes suggests the golfer adopts a wider, more stable stance (Leadbetter, 1993; Hunter, 2010; Harmon, 2011), which was found to be the case for low handicap golfers (Blenkinsop et al., 2018). In the present study there was no evidence that the participants adopted a wider stance in the sloped conditions. Although there was not a consistent response across all participants, nine out of the 12 golfers adopted a narrower stance on the downhill slope compared to the other two conditions (Table 4). A narrower base of support would lead to a less stable system (Hay, 1985). Blenkinsop et al. (2018) speculated that higher handicap golfers may be more prone to changing the pattern of the COP due to being less skilled at balancing than their low handicap counterparts. Low handicap golfers have been found to have better balance than high handicap golfers in both static (Sell, Tsai, Smoliga, Myers \& Lephart, 2007) and dynamic (Choi et al, 2016) tests of balance.

Ball and Best (2007) analysed COP movement for golfers using a driver, on the flat, and found the majority of players (approx. 63\%) had a shift in COP from back foot to front foot from the top of the backswing through ball contact (Figure 1). A smaller group of players (approx. 31\%) followed the same pattern during the downswing but shifted the COP towards the back foot at ball contact, categorised as the 'reverse' group. Ball and Best (2011) found these patterns were present for players across a range of different clubs (driver, 3-iron and 7 -iron), with over $90 \%$ of players maintaining their group with each club. Blenkinsop et al. (2018) found that two out of 12 golfers changed to the reverse group with the introduction of an uphill slope, and speculated that higher handicap golfers may be more likely to change to the reverse group since they may be less able to adapt to the slope. That is, since the slope caused a shift to the lower foot, it was speculated that the shift to the lower foot would be exaggerated in the less skilled golfers, due to a lack of balance (Choi et al., 2010), leading to more of the group switching to the reverse pattern. A switch to the reverse group when playing from an uphill slope was not found to be the case in the present study. The reason the high handicap group did not switch to the reverse group is in part due to the golfers being unable to maintain the shift of weight (and COP) towards the back foot on an uphill slope (Figure 4). By remaining upright, rather than perpendicular to the slope as recommended in the coaching literature, an exaggerated shift of the COP to the back foot and hence transition to the reverse pattern was not achieved. It would be interesting to determine whether a change in pattern could be induced through more extreme slopes and to determine the threshold of slope required for such a change. It is likely that this threshold will vary for different golfers of different abilities. However, if 
the high handicap golfers are unable to achieve the recommended stance (i.e. perpendicular to the slope), a change in pattern is unlikely.

There were no statistically significant differences in ball speed, azimuth, or shot distance between the three conditions (Table 5). Coaching literature often recommends 'taking an extra club' (e.g. taking a five-iron rather than a six-iron, which is a longer club with less loft on the clubface) when playing on an uphill slope as the increased ball height, due to an increased launch angle, will lead to a reduction in shot distance (Leadbetter, 1993; Harmon, 2011). A statistically significant difference was found for launch angle across all conditions, but not for shot distance (carry or total). There were significant differences for side spin rate and offline displacement for uphill versus downhill slopes (Table 5). Significant changes in offline displacement and side spin suggest that, compared to downhill, uphill shots result in increased spin and movement of the ball towards the left of target, for right handed golfers. Downhill shots resulted in more side spin of the ball to the right and continued, but reduced, movement of the ball to the left. With very little change in azimuth between conditions, these results suggest the increased movement of the ball to the left for uphill shots was most likely due to the increased side spin of the ball to the left, and the reduction of movement to the left from a downhill slope was most likely due to increased side spin of the ball to the right. A similar result was found for low handicap golfers, however, the range of off line distances was greater for the high handicap golfers, as might be expected (Table 2).

To counter the effects of side spin placed on the ball from a sloping lie the coaching literature suggest that golfers compensate by rotating the trunk to the right or left of the target for uphill and downhill slopes, respectively. No differences were found in the alignment of the feet and the shoulders (Table 4) relative to the straight target for the sloped conditions at address (TA). However, for the downhill condition there was a significant change in alignment of the hips at address compared to the flat and the uphill condition (Table 4), with the hips turned to the right of the target. This is in the opposite direction to the compensation recommended by Harmon (2011). As this is only a small difference, it may in part be due to the change in position of the golf ball within the stance, however, if this were the case it might be expected to see a similar change in alignments at the shoulders. At ball contact there were no significant differences in hip alignment across the three slope conditions (Table 4). All golfers rotated the hips to an open angle (pointing left of target) at ball contact (range $-5^{\circ}$ to $42^{\circ}$ ), whereas there was a mix of open and closed angles at the shoulders (range $-11^{\circ}$ to $10^{\circ}$ ), as found previously for shots from a flat surface (Burden et al., 1998) and from slopes (Blenkinsop et al., 2018).

Given the challenging nature of playing from a slope, it might be expected that the high handicap golfers are more variable when playing from these conditions. When comparing performance outcomes between the low and high handicap groups, the high handicap golfers were indeed more variable (Table 2) in terms of ball speed and distances (carry, total and range of offline). However, when comparing the variation (standard deviations) of high handicap golfers across slope conditions there were no statistically significant differences (Table 5). Similarly, when comparing the variation in COP at the defined swing events, there were very few statistically significant differences (Table 3). The golfers were less variable in the COP location at ball contact when playing from a downhill slope (Table 3). This may be due to the constraint of having a narrower stance on the downhill slope. The overall lack of differences in COP variability may also be due to the randomised order of slope conditions. A different experimental design would be required to answer the question relating to variability when playing from a slope. In the present study the $5^{\circ}$ slope used in the current 
analysis was based on the average slope experienced when playing on a course (Peters et al., 2015). The $5^{\circ}$ slope may be within the comfort zone of the golfers, and more extreme slopes may be required to induce a change in consistency and performance. However, the $5^{\circ}$ slope may be sufficient to induce changes in consistency of performance outcomes for even higher handicap golfers. The present study used an intermediate group with a range of handicap from $10-15$, whereas the highest handicap permissible for a male golfer is 54 (CONGU, 2018). To fully understand the relationship between expertise (as denoted by handicap) and the effect of a slope requires further investigation.

\section{CONCLUSION}

The most notable difference between higher and lower handicap golfers playing from uphill and downhill slopes, apart from the expected differences in shot outcomes (ball speed, shot distance and range of off line distance), was that the higher handicap golfers were unable to maintain the COP shift achieved at take away throughout the whole golf swing (Figure 4, Table 3). Rather than maintaining the shift towards the lower foot, by the time the golfer had reached the top of the backswing the weight distribution, measured by COP, was the same as playing on the flat. This difference, compared to the low handicap golfers (Figure 1), increases the likelihood of striking the ground before the ball on a downhill slope. Higher handicap golfers should be encouraged to follow the coaching advice, but should be reminded to maintain these changes throughout the swing and not just at take away (address). The higher handicap golfers did follow the coaching advice of where to place the ball in the stance on a slope, but a large proportion of golfers achieved this on the downslope by narrowing the stance. A narrow stance potentially leads to a less stable situation. It would therefore be of interest to look at whether this affects the balance of the high handicap golfers compared to their more skilled colleagues, before advising them to widen their stance as the coaching literature recommends.

\section{ACKNOWLEDGEMENTS}

The authors would like to thank the golfers who participated in the study for their time and Lorna Belford for her assistance in the data collection.

\section{REFERENCES}

Ball, K.A., \& Best, R.J. (2007). Different centre of pressure patterns within the golf stroke I: Cluster analysis. Journal of Sports Sciences, 25(7), 757-770.

Ball, K.A. \& Best, R.J. (2007b). Different centre of pressure patterns within the golf stroke II: Group-based analysis. Journal of Sports Sciences, 25(7), 771-779.

Ball, K.A. \& Best, R.J. (2011). Golf styles and centre of pressure patterns when using different golf clubs. Journal of Sports Sciences, 29(6), 587-590.

Ball, K.A., \& Best, R.J. (2012). Centre of pressure patterns in the golf swing: individualbased analysis. Sports Biomechanics, 11(2), 175-189.

Ball, K.A., Best, R.J., \& Wrigley, T. (2001). Centre of pressure correlations with clubhead speed in the golf swing. In Blackwell JR, Sanders $\mathrm{RH}$, eds. XIX Proceedings of the Symposium of the International Symposium on Biomechanics in Sport. 48-53.

Blenkinsop, G.M., Liang, Y., Gallimore, N.J. \& Hiley, M.J. (2018). The Effect of uphill and downhill slopes on weight transfer, alignment and shot outcome in golf. Journal of Applied Biomechanics, 34, 361-368. 
Bradshaw, E.J., Keogh, J.W.L., Hume, P.A., Maulder, P.S., Nortje, J., \& Marnewick, M. (2009). The effect of biological movement variability on the performance of the golf swing in high- and low-handicapped players. Research Quarterly for Exercise and Sport, 80, 185-196.

Burden, A.M., Grimshaw, P.N. \& Wallace, E.S. (1998). Hip and shoulder rotations during the golf swing of sub-10 handicap players. Journal of Sports Sciences, 16, 165-176.

Cheetham, P.J., Martin, P.E., Mottram, R.E. \& St Laurent, B.F. (2000). The importance of stretching the 'X-Factor' in the downswing of golf: the 'X-Factor stretch'. In P.R. Thomas (ed), Optimising Performance in Golf, 192-199. Brisbane, Australia: Australian Academic Press.

Choi, A., Sim, T. \& Mun, J.H. (2016). Improved determination of dynamic balance using the centre of mass and centre of pressure inclination variables in a complete golf swing cycle. Journal of Sports Sciences, 34(10), 906-914.

CONGU. (2018). A quick guide to the CONGU® handicapping system. The Council of National Golf Unions. Retrieved from: http://www.congu.co.uk/wpcontent/uploads/2017/12/Players-quick-guide-2018.pdf

Field, A.P. (2009). Discovering statistics using SPSS. London, England: SAGE.

Fradkin, A.J., Sherman, C.A. \& Finch, C.F. (2004). How well does club head speed correlate with golf handicaps? Journal of Science Medicine and Sport, 7, 465-472.

Harmon, B. (2011). Four shots for beating the slope. Retrieved from https://www.golfdigest.com/story/butch-harmon-uneven-lies

Healy, A., Moran, K.A., Dickson, J., Hurley, C., Smeaton, A.F., O'Connor, N.E., Kelly, P., Haahr, M. \& Chockalingam, N. (2011). Analysis of the 5 iron golf swing when hitting for maximum distance. Journal of Sports Sciences, 29(10), 1079-1088.

Hunter, R. (2010). Junior Golf Coaching with Rupert Hunter. Series 2: Lesson Seven Awkward Lies. Golf Today, Hunter Knight Golf Coaching.

Kenny, I.C., McCloy, A.J., Wallace, E.S., \& Otto, S.O. (2008). Segmental sequencing of kinetic energy in a computer-simulated golf swing. Sports Engineering, 1, 37-45.

Koenig, G., Tamres, M., \& Mann, R.W. (1993). An analysis of the kinetics and kinematics of the golf swing. In Hamill J, ed., XI Proceedings of the Symposium of the International Society of Biomechanics in Sports. 328 - 333 .

Koslow, R. (1994). Patterns of weight shift in the swings of beginning golfers. Perceptual and Motor Skills, 79, $1296-1298$.

Leadbetter, D. (1993). Faults and fixes: The golfer's essential problem-solving manual. London: Collins Willow.

McNitt-Gray, J.L., Munaretto, J., Zaferiou, A, Requejo, P.S. \& Flashner, H. (2013). Regulation of reaction forces during the golf swing. Journal of Sports Sciences, 12(2), 121-131.

Myers, J., Lephart, S., Tsai, Y.S., Sell, T., Smoliga, J. \& Jolly, J. (2007). The role of upper torso and pelvis rotation in driving performance during the golf swing. Journal of Sports Sciences, 1, 1-8.

Okuda, I., Gribble, P. \& Armstrong, C. (2010). Trunk rotation and weight transfer patterns between skilled and low skilled golfers. Journal of Sports Science and Medicine, 9, 127-133.

Peter, R., Smith. M. \& Lauder, M. (2015). Quantifying the gradients exposed to a professional golfer during a round of golf. In Colloud F, Domalain M, Monnet T, eds. 33rd International Conference on Biomechanics in Sports. 1153-1156. 
Peterson, T.J. \& McNitt-Gray, J.L. (2018). Regulation of linear and angular impulse with modified address positions during the golf swing. Journal of Applied Biomechanics, (in press).

Preuss, R., \& Fung, J. (2004). A simple method to estimate force plate inertial components in a moving surface. Journal of Biomechanics, 37(8), 1177-1180.

Richards, J., Farrell, M., Kent, J. \& Kraft, R. (1985). Weight transfer patterns during the golf swing. Research Quarterly for Exercise and Sport, 56(4), 361-365.

Sell, T.C., Tsai, Y.S., Smoliga, J.M., Myers, J.B., \& Lephart, S.M. (2007). Strength, flexibility, and balance characteristics of highly proficient golfers. Journal of Strength and Conditioning Research, 21(4), 1166-1171.

Wallace, E.S., Graham, D., \& Bleakley, E.W. (1990). Foot to ground pressure patterns during the golf drive: A case study involving a low handicap player and a high handicap player. In Cochran AJ, ed. Science and golf: Proceedings of the First World Scientific Congress of Golf. 25-29.

Wheat, J.S., Vernon, T. \& Milner, C.E. (2007). The measurement of upper body alignment during the golf drive. Journal of Sports Sciences., 25, 749-755.

Winter DA. (1995) Human balance and posture control during standing and walking. Gait Posture, 3(4), 193-214.

Zheng, N., Barrentine, S.W., Fleisig, G.S. \& Andrews, J.R. (2008). Kinematic analysis of swing in pro and amateur golfers. International Journal of Sports Medicine, 29, 487-493. 